\title{
Estimativas de parâmetros genéticos da qualidade fisiológica de sementes de genótipos de soja produzidas em diferentes regiões de Minas Gerais
}

\section{Genetics parameters estimates of seeds physiologic quality of soybean genotypes grown in different areas of Minas Gerais}

\author{
Edmar Soares de Vasconcelos ${ }^{1 *}$; Múcio Silva Reis ${ }^{2}$; \\ Tuneo Sediyama²; Cosme Damião Cruz ${ }^{3}$
}

\section{Resumo}

O estudo quantitativo de diferentes características agronômicas é importante em programas de melhoramento de plantas. Todavia, a estimativa de parâmetros genéticos relacionados à qualidade fisiológica de sementes tem sido pouco explorada, com escassez de informações na literatura. O objetivo deste trabalho foi estimar parâmetros genéticos da qualidade fisiológica de sementes de três cultivares e quatorze linhagens de soja, com ciclo de maturação tardio, que participaram de cinco ensaios finais de avaliação de linhagens, do Programa de Melhoramento Genético de Soja do Departamento de Fitotecnia da UFV. Os ensaios foram conduzidos em Tupaciguara, Florestal, Unaí e dois locais em Capinópolis, no estado de Minas Gerais, no ano agrícola 2000/2001. O delineamento experimental utilizado foi em blocos ao acaso com três repetições. A qualidade fisiológica das sementes foi avaliada pelo teste de germinação e de emergência de plântulas em leito de areia. Os parâmetros genéticos estimados foram componente quadrático genotípico, componente de variância genótipos $\mathrm{x}$ ambientes, coeficiente de determinação genotípico, coeficiente de variação genético. A germinação das sementes das cultivares FT 104, Doko-RC e Conquista e das linhagens UFV97-61190916 e UFV98-CR67 foi maior que 85\% em todos os ambientes. Os coeficientes de determinação genotípico, obtidos a partir dos dados de germinação de sementes e de emergência de plântulas, variaram entre ambientes. A seleção individual de genótipos de soja, com base na qualidade fisiológica das sementes por local, pode propiciar maiores ganhos quando comparado à seleção em que se consideram todos os ambientes conjuntamente.

Palavras-chave: Glycine max, coeficiente de determinação genotípico, coeficiente de variação genético, genética da soja

\begin{abstract}
The quantitative study of different agronomic characteristics is of great importance in plant breeding programs. However the estimation of genetic parameters related to seed physiologic quality has been little explored and works of that are scarec in the literature. The objective in this work was to estimate genetic parameters for seed physiologic quality of three soybean cultivars and fourteen lineages, with late maturation cycle, that are part of five final experiments of lineages evaluation from the Program of Genetic Improvement of Soybean of the Department of Fitotecnia of UFV, led in Tupaciguara, Florestal, Unaí and two places in Capinopolis, state of Minas Gerais, in the agricultural year 2000/2001. The
\end{abstract}

\footnotetext{
Prof. do Dept ${ }^{\circ}$ de Agronomia da Universidade Estadual do Oeste do Paraná, UNOESTE. Marechal Cândido Rondon, PR. E-mail: vasconceloses@pop.com.br

2 Profs. do Dept ${ }^{\circ}$ de Fitotecnia, Universidade Federal de Viçosa, UFV, Viçosa, MG. E-mail: msreis@ufv.br; tuneo@ufv.br

3 Prof. do Dept ${ }^{\circ}$ de Biologia Geral, UFV, Viçosa, MG. E-mail: cdcruz@ufv.br

Autor para correspondência
} 
experimental design was random blocks, with three repetitions. The genetic parameters estimates were quadratic genotypic component, genotype $\mathrm{x}$ environments variance component, genotypic determination coefficient and genetic variation coefficient. The seeds physiologic quality was evaluated by germination test and seedling emergence on sand substrate. The seeds of cultivars FT 104, Doko-RC, Conquista and of lineages UFV97-61190916, UFV98-CR67 had germination over $85 \%$ in all the environmentsl. The genotypic determination coefficients based on seed germination and seedling emergence varied among the environments. The individual selection of soybean genotypes, based on the seed physiologic quality by locality, can lead to higher gains than joint selection considering all environments.

Key words: Glycine max, genotypic determination coefficient, genetic variation coefficient, soybean genetic

\section{Introdução}

A estimativa de parâmetros genéticos e fenotípicos, como herdabilidade, correlação genética e fenotípica e ganhos com a seleção, é importante em programas de melhoramento genético. Isto possibilita a escolha de métodos e caracteres utilizados nas etapas iniciais e avançadas de programas de melhoramento, permitindo ainda, estudar mecanismos, valores genéticos e variabilidade para um caráter (CILAS et al., 1998; BONATO; VELLO, 1999; COIMBRA; GUIDOLIN; CARVALHO, 1999; GRAVINA et al., 2004). No entanto, características como germinação de sementes e emergência de plântulas de soja, são pouco estudadas, quantitativamente.

Delineamentos experimentais são utilizados para avaliar e comparar características quantitativas de famílias segregantes ou linhagens melhoradas (GOMES, 1985). Blocos casualizados são utilizados para representar famílias ou linhagens $r$ vezes em avaliações genéticas. Tais $r$ repetições fornecem estimativas das variações ambientais para serem extrapoladas, como componentes da variação fenotípica entre famílias ou linhagens e possibilitam o estudo de parâmetros genéticos no melhoramento de plantas (CRUZ; REGAZZI, 1997).

Estimativas da herdabilidade ampla de características de plantas são importantes por terem relação com a seleção e quanto maior o valor estimado desse parâmetro, maior será a chance de sucesso com a seleção (STRICKBERGER, 1985; GRAVOIS; BERNHARDT, 2000).

Neste trabalho, objetivou-se estimar os parâmetros genéticos da qualidade fisiológica de sementes, avaliada pelos testes de germinação e emergência de plântulas em leito de areia, de cultivares e linhagens de soja cultivadas em diferentes ambientes no estado de Minas Gerais.

\section{Material e Métodos}

\section{Locais de condução dos experimentos}

Foram avaliadas sementes de 14 linhagens e três cultivares de soja, de ciclo da maturação tardio, pertencentes aos ensaios finais de avaliação do comportamento agronômico (EFIs) do Programa de Melhoramento de Soja do Departamento de Fitotecnia da Universidade Federal de Viçosa, conduzidos no estado de Minas Gerais, no ano agrícola 2000/2001.

Os ensaios foram conduzidos em cinco locais (ambientes) dentro do estado de Minas Gerais: Capinópolis 1 (em Latossolo vermelho eutroférrico), Capinópolis 2 (em Latossolo vermelho distroférrico, de maneira que o tipo de solo diferencia ambos ambientes de Capinópolis), Tupaciguara, Florestal e Unaí, com as cultivares: Conquista, Doko-RC e FT 104, e as linhagens: UFV97-6119091, UFV9761190914, UFV97-61190916, UFV97-6129726, UFV97-6129729, UFV97-612977215, UFV98267F10RC1,3, UFV98-467150, UFV98-CR67, UFV98-CR75, UFV98-CRC1,17, UFV99-60228, UFV99-61270 e UFV99-806241. O delineamento experimental foi o de blocos casualizados, com três repetições. Cada parcela foi constituída por quatro linhas de cinco metros de comprimento, com espaçamento de $0,5 \mathrm{~m}$ entre linhas. A colheita das plantas foi feita nas duas linhas centrais, com quatro metros de comprimento, em área útil de $4,0 \mathrm{~m}^{2}$. 


\section{Teste de germinação}

O teste de germinação (TG) foi realizado 25 dias após a colheita das sementes, sendo utilizado 200 sementes de cada genótipo por repetição de campo, sendo as sementes divididas em quatro subamostras de 50, de acordo com critérios das Regras para Análise de Sementes (BRASIL, 1992). Rolo de papel tipo "germitest" foi o substrato utilizado, umedecido com água deionizada em 2,5 vezes o seu peso, sendo a semeadura feita em três folhas por rolo. A seguir, os rolos foram colocados em germinador à temperatura de $25^{\circ} \mathrm{C} \pm 1^{\circ} \mathrm{C}$. A contagem de plântulas normais foi feita aos cinco e oito dias após a montagem do teste. Os resultados foram expressos em porcentagem de plântulas normais.

\section{Emergência de plântulas em leito de areia}

O teste foi realizado em condições de casa de vegetação, com 200 sementes de cada genótipo, por repetição de campo. As sementes foram dispostas em cinco sulcos, em bandejas de polietileno, com areia lavada e esterilizada com brometo de metila, com 40 sementes por sulco a $1,5 \mathrm{~cm}$ de profundidade. A irrigação foi realizada quando necessário, para manutenção de umidade favorável à germinação das sementes.

$\mathrm{O}$ número de plântulas de soja emergidas foi contado, quando as mesmas apresentavam o primeiro par de folhas (unifolioladas) completamente abertas. Os resultados foram expressos em porcentagem de plântulas normais, de acordo com o estabelecido pelas Regras para Análise de Sementes (BRASIL, 1992).

Análise de normalidade e homogeneidade de variância

Os dados da germinação de sementes e de emergência em leito de areia foram submetidos ao teste de normalidade (teste de Lilliefors) para verificação da necessidade ou não da transformação dos mesmos. O teste de Cochram foi realizado para confirmar ou não a homogeneidade de variância e a necessidade de ajuste dos graus de liberdade, permitindo a análise conjunta dos dados dos diferentes ambientes.

As análises de variância individuais e conjunta foram realizadas com dados transformados (Tabela 1), e o efeito do genótipo foi considerado fixo nas análises, e os demais, exceto a média, aleatórios. As médias foram comparadas pelo teste de Tukey a 5\% de probabilidade $(\mathrm{p}<0,05)$.

\section{Estimativa dos parâmetros genéticos}

Os parâmetros genéticos por local foram estimados por: componente quadrático genotípico - $\hat{\phi}_{g}=(\mathrm{QMG}-\mathrm{QMR}) / \mathrm{r} ; \quad$ variância residual $\hat{\sigma}^{2}=$ QMR ; coeficiente de determinação genotípico $(\%): \mathrm{H}^{2}=\left[\hat{\phi}^{2} /(\mathrm{QMG} / \mathrm{r})\right] \mathrm{x} 100$.

Os parâmetros genéticos, estimados a partir da análise conjunta, foram obtidos por: componente quadrático genotípico: $\hat{\phi}_{g}=(\mathrm{QMG}-\mathrm{QMR}) / \mathrm{ar}$; componente de variância genótipos $\mathrm{x}$ ambientes: $\hat{\sigma}_{g a}^{2}=(\mathrm{g}-1)(\mathrm{QMGA}-\mathrm{QMR}) / \mathrm{rg}$; variância residual: $\hat{\sigma}^{2}=\mathrm{QMR}$; coeficiente de determinação genotípico (\%): $\quad H^{2}=\left[\hat{\phi}_{\mathrm{g}} /(\mathrm{QMG} / \mathrm{ar})\right] \times 100 ;$ coeficiente de variação genético $(\%): \mathrm{CV}_{\mathrm{g}}=\left(100 \sqrt{\hat{\phi}_{g}}\right) / \mathrm{M}$; razão entre $\mathrm{CV}_{\mathrm{g}}$ e CV: Razão $=\mathrm{CV}_{\mathrm{g}} / \mathrm{CV}_{\mathrm{e}}$.

As estimativas dos parâmetros genéticos, com os dados transformados da germinação de sementes e de plântulas emergidas em leito de areia, foram obtidos pela análise conjunta dos ambientes em que foram conduzidos os experimentos do ano agrícola 2000/2001 (Tabela 6), uma vez que as variâncias nos diferentes locais apresentaram homogeneidade.

As análises genético/estatísticas foram realizadas com o aplicativo computacional "Genes" (CRUZ, 2006). 
Tabela 1. Esquema resumido da análise de variância individual e conjunta dos dados de germinação de sementes e emergência de plântulas de soja em leito de areia.

\begin{tabular}{|c|c|c|c|}
\hline Fontes de Variação & Graus de liberdade & $\mathrm{E}(\mathrm{QM})$ & $\mathrm{F}$ \\
\hline & \multicolumn{3}{|c|}{ Individual } \\
\hline Blocos & $r-1$ & $\sigma^{2}+\mathrm{g} \sigma_{\mathrm{b}}^{2}$ & \\
\hline Genótipos (G) & $g-1$ & $\sigma^{2}+\mathrm{b} \phi_{\mathrm{g}}$ & QMG/QMR \\
\hline Resíduo & $(g-1)(r-1)$ & $\sigma^{2}$ & \\
\hline Média & & M & \\
\hline \multirow[t]{2}{*}{ Coef. Variação (CV. \%) } & & $(100 \sqrt{\mathrm{QMR}}) \mathrm{M}$ & \\
\hline & \multicolumn{3}{|c|}{ Conjunta } \\
\hline Blocos/Ambiente & $(\mathrm{r}-1) \mathrm{a}$ & $\sigma^{2}+g \sigma_{b}^{2}$ & \\
\hline Ambientes (A) & $a-1$ & $\sigma^{2}+g \sigma_{b}^{2}+g r \sigma_{a}^{2}$ & $\mathrm{QMA} / \mathrm{QM}(\mathrm{B} / \mathrm{A})$ \\
\hline Genótipos $(\mathrm{G})$ & $g-1$ & $\sigma^{2}+\mathrm{r} \ell \sigma_{\mathrm{ga}}^{2}+\operatorname{ar} \phi_{g}$ & QMG/QMGA \\
\hline GxA & $(a-1)(g-1)$ & $\sigma^{2}+\mathrm{r} \ell \sigma_{\mathrm{ga}}^{2}$ & QMGA/QMR \\
\hline Resíduo & $(\mathrm{g}-1)(\mathrm{r}-1) \mathrm{a}$ & $\sigma^{2}$ & \\
\hline Média & \multicolumn{3}{|c|}{$\mathrm{M}$} \\
\hline Coef. Variação (CV. \%) & \multicolumn{3}{|c|}{$(100 \sqrt{\mathrm{QMR}}) \mathrm{M}$} \\
\hline
\end{tabular}

$\ell=\mathrm{g} /(\mathrm{g}-1)$.

$\sigma^{2}$ : Componente de variância residual; $\sigma_{\mathrm{b}}^{2}$ : Componente de variância relativo aos blocos; $\sigma_{\mathrm{a}}^{2}$ : Componente de variância ambiental (localidade); $\sigma_{\mathrm{ga}}^{2}$ : Componente de variância da interação entre genótipo e ambiente, e; $\phi_{g}$ : Componente quadrático genotípico.

\section{Resultados e Discussão}

O teste Lilliefors demonstrou que os dados não apresentavam normalidade e, por isto, foram transformados em arco seno $\sqrt{x / 100}$, com $\mathrm{x}$ correspondendo à porcentagem de sementes germinadas ou de plântulas de soja que emergiram (GOMES, 1985) (Tabelas 3 e 4).

\section{Germinação}

O quociente entre o maior quadrado médio residual e o menor foi de 1,931, para os dados transformados de sementes germinadas. $O$ valor deste quociente foi menor que sete e, assim, a análise de variância conjunta dos diferentes locais foi realizada sem o ajuste dos graus de liberdade do resíduo e da interação (Tabela 2), conforme recomendação apresentada por Gomes (1985). 
Tabela 2. Resumo da análise de variância conjunta dos dados de germinação (TG) e de emergência de plântulas (ELA), transformados em arco seno da raiz de $\mathrm{x} / 100$, de sementes de cultivares e linhagens de soja oriundas dos EFIs de ciclo tardio do ano agrícola de 2000/2001 no Estado de Minas Gerais.

\begin{tabular}{|c|c|c|c|c|c|c|c|}
\hline \multirow{2}{*}{ Fontes de variação } & \multirow[b]{2}{*}{ GL } & \multicolumn{3}{|c|}{$\mathrm{TG}^{1}$} & \multicolumn{3}{|c|}{ ELA $^{2}$} \\
\hline & & QM & \multicolumn{2}{|l|}{$\mathrm{F}$} & QM & \multicolumn{2}{|l|}{$\mathrm{F}$} \\
\hline Blocos/Ambientes & 10 & 0,0053 & & & 0,0173 & & \\
\hline Genótipos (G) & 16 & 0,0304 & 1,7581 & $*$ & 0,0491 & 2,3343 & $* *$ \\
\hline Ambientes (A) & 4 & 0,7234 & 135,5729 & $* *$ & 0,4269 & 24,6579 & $* *$ \\
\hline $\mathrm{G} \times \mathrm{A}$ & 64 & 0,0173 & 2,0175 & $* *$ & 0,0210 & 2,6977 & $* *$ \\
\hline Resíduo & 160 & 0,0086 & & & 0,0078 & & \\
\hline Total & 254 & & & & \multirow{2}{*}{\multicolumn{2}{|c|}{$1,2522(88,60 \%)$}} & \\
\hline Média $^{3}$ & & \multicolumn{3}{|c|}{$1,2684(89,27 \%)$} & & & \\
\hline CV. $(\%)$ & & \multicolumn{3}{|c|}{7,29} & \multicolumn{3}{|c|}{7,05} \\
\hline
\end{tabular}

${ }^{1}$ Teste de germinação; ${ }^{2}$ Teste de emergência em leito de areia; *Significativo a $5 \%$ de probabilidade pelo teste $\mathrm{F} ;$ ** Significativo a $1 \%$ de probabilidade pelo teste $\mathrm{F}$.

${ }^{3}$ Média transformada (arco seno da raiz de $\mathrm{x} / 100$ ) e original, entre parêntesis.

A porcentagem de germinação média das sementes de soja $(89,27 \%)$ foi maior que o exigido para a comercialização de sementes no Brasil, que é de $80 \%$, conforme normatização da Secretaria de Estado da Agricultura e do Abastecimento na resolução n. 051 de 1986 (CARRARO; PESKE, 2005).

O coeficiente de variação dos dados transformados, para a característica germinação de sementes $(7,29 \%)$ foi menor que o observado para a germinação de sementes de soja (17\%) em Selvíria, Mato Grosso do Sul (LACERDA et al., 2003), evidenciando que o experimento gerou erros aceitáveis para o estudo desta característica.

A interação genótipos $\mathrm{x}$ ambientes, para os dados transformados de germinação das sementes foi significativa (Tabela 2), evidenciando comportamento variado dos genótipos nos diferentes ambientes. Em função de tal significância, o desdobramento da interação foi realizado para verificar a resposta de cada genótipo por ambiente (Tabelas 3 e 4).

Interações significativas têm sido freqüentemente relatadas na literatura, seja para produção de grãos, qualidade de sementes, comportamento de materiais genéticos distintos, resistência à doenças entre outras (HEGSTAD; BOLLERO; NICKELL, 1999; SOOD et al., 1999; YANG et al., 2001, LIMA et al., 2008; PÁDUA et al., 2010).

Os dados transformados, para a característica germinação das sementes do grupo de genótipo, nos diferentes ambientes, propiciaram constatação de maior germinação média para aquelas colhidas em Tupaciguara (Tabela 3). Isto demonstra a influência do ambiente na qualidade das sementes, já que as semente de Tupaciguara apresentaram germinação mínima de 96,67\%, e em Florestal foi verificado genótipo com apenas $62,50 \%$ de sementes germinadas.

Avaliando apenas os locais Rio Paranaíba, Florestal e Capinópolis, verifica-se que as sementes colhidas em Rio Paranaíba apresentam maiores porcentagens de germinação que as colhidas em Florestal e Capinópolis (Tabela 3), esse resultado concorda com o relatado de Santos et al. (2001) em estudos anteriores com soja no estado de Minas Gerais. Diante da necessidade de produzir sementes de soja, uma boa opção seria produzir em Rio Paranaíba, já que não se trata do primeiro relato de produção de sementes com maior poder germinativo que as produzidas em Florestal e Capinópolis. 


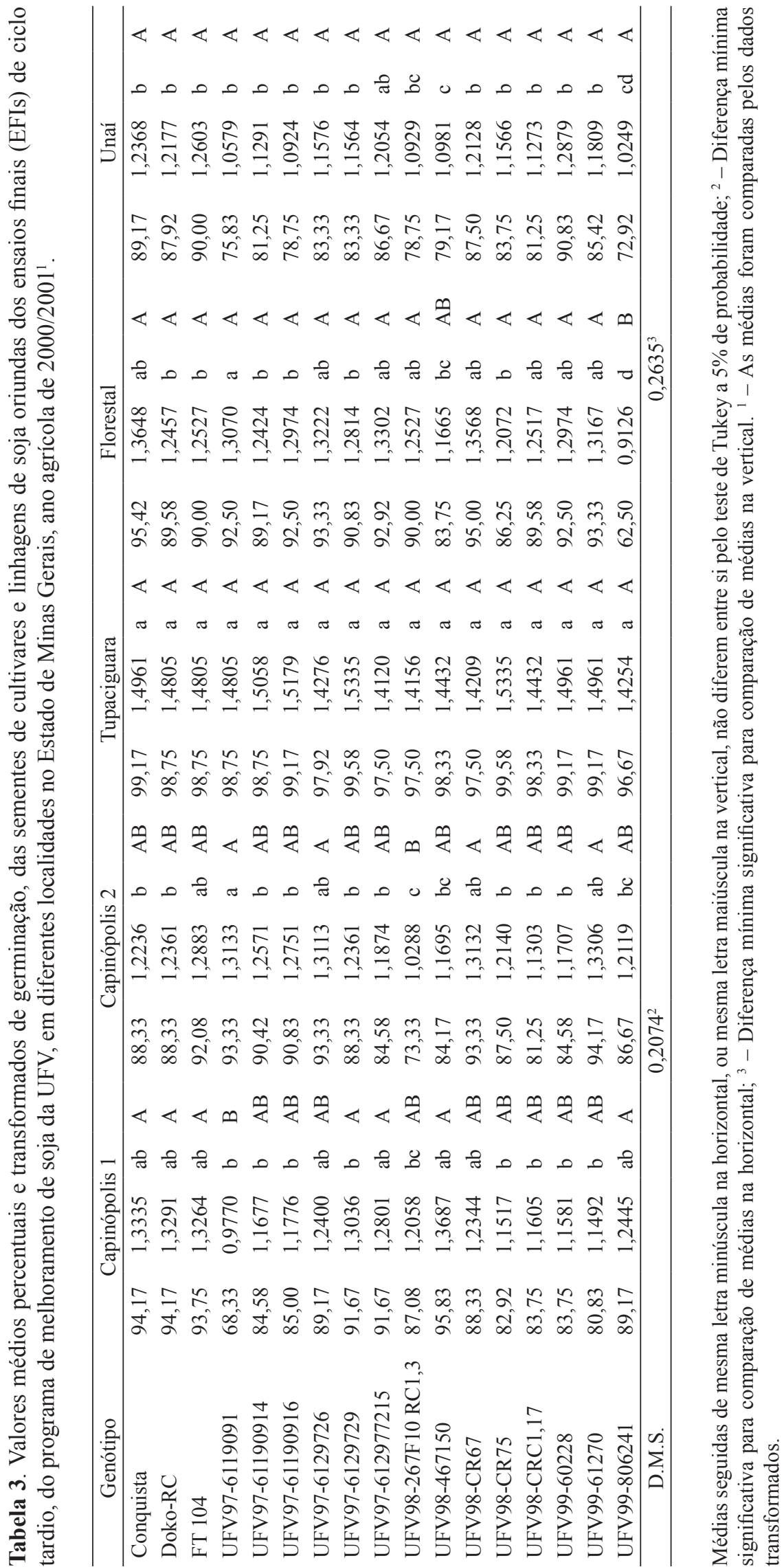




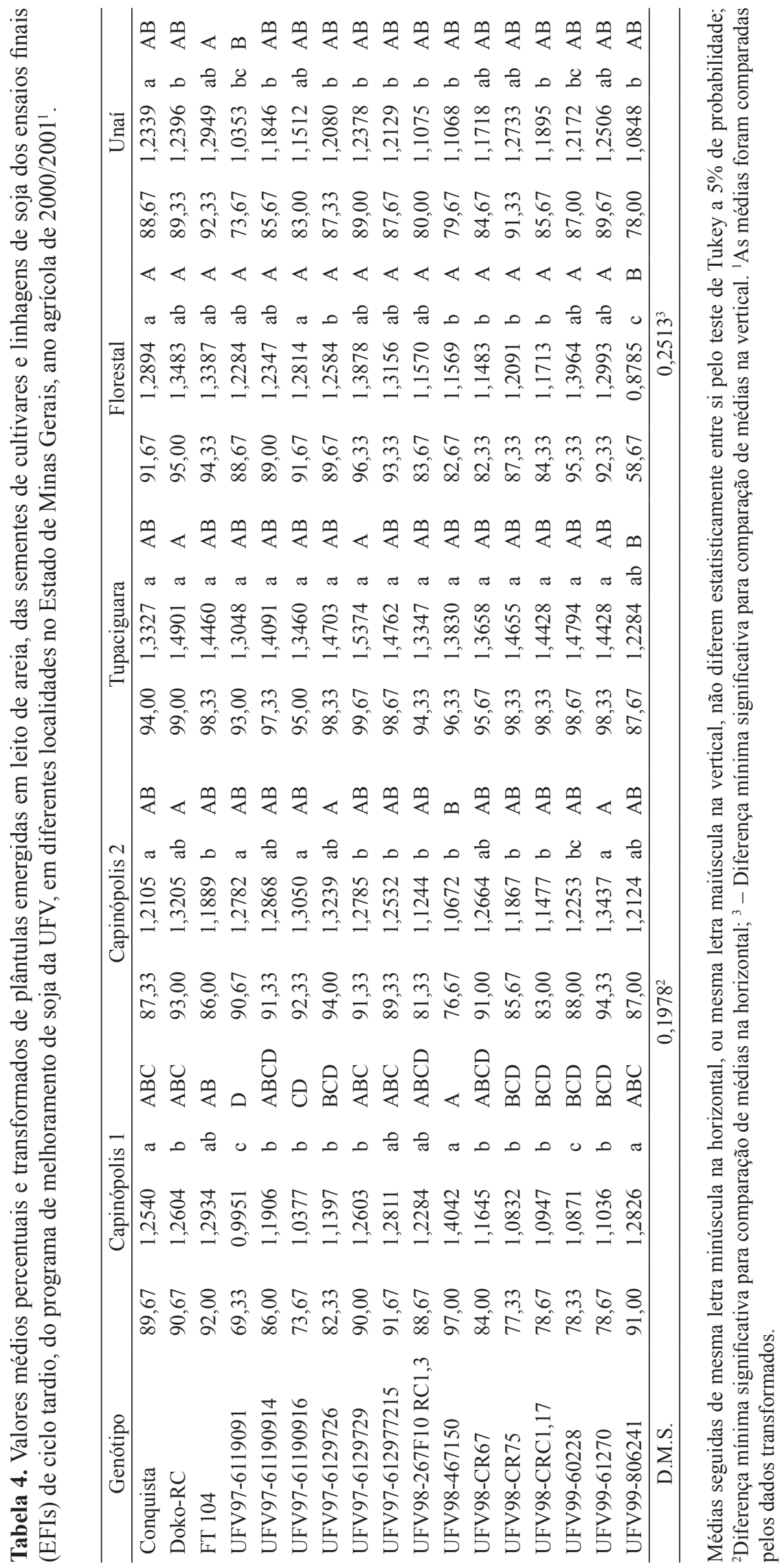


As cultivares Conquista, Doko-RC e FT 104, e as linhagens UFV97-6129729, UFV97-612 977215, UFV98-467150 e UFV99-806241 apresentaram maiores índices transformados de germinação em Capinópolis 1 (94,17; 94,17; 93,75; 91,67; 91,67; 95,83 e $89,17 \%$, respectivamente). As linhagens UFV97-6119091, UFV97- 6129726, UFV98CR67 e UFV99-61270 apresentaram maiores índices de germinação $(93,33 ; 93,33 ; 93,33 ; 94,17$, respectivamente) em Capinópolis 2. No entanto os genótipos tiveram valores transformados de germinação semelhantes, tanto em Tupaciguara quanto em Unaí. Dentre esses, as sementes dos genótipos Doko-RC, Conquista, FT 104, UFV9761190916 e UFV98-CR67 apresentaram germinação superior a $85 \%$ em todos os ambientes. O genótipo FT 104 teve germinação de sementes acima de 90\% em todos eles. Esses genótipos apresentaram os melhores comportamentos para a germinação de sementes se considerando os ambientes como um todo. Também pode acontecer da porcentagem de germinação das sementes mudar de acordo com a época de semeadura (PEREIRA; PEREIRA; FRAGA, 2000) fator que deve ser considerado no planejamento de produção de sementes.

O genótipo UFV99-806241 teve menor índice transformado de germinação em Florestal (Tabela 3) com germinação de 62,50, sendo dessa forma um genótipo não adaptado às condições ambientais desse local.

As sementes de cultivares e linhagens de soja colhidas em Florestal apresentaram a maior estimativa do componente quadrático genotípico da germinação das sementes $(0,0071)$, seguida por Capinópolis $1(0,0059)$ (Tabela 5). As sementes das cultivares e linhagens de soja colhidas em Florestal apresentaram o maior coeficiente de determinação genotípico para germinação $(66,61 \%)$, seguidas pelo ensaio de Capinópolis1 (62,49\%). Vale ressaltar que nesses locais com maior magnitude da relação entre a variabilidade genética da germinação de sementes e a variância total do experimento, a prática da seleção possivelmente trará maior ganho genético para a próxima geração, assim deve-se priorizar esses locais no momento da seleção de genótipos com maior germinação de sementes.

O coeficiente de determinação genotípico foi zero em Tupaciguara, com quadrado médio de genótipos e do resíduo semelhantes, o que resulta em componente quadrático genotípico igual a zero. Isto pode ser explicado pelas condições satisfatórias desse ambiente, já que todos os genótipos de soja apresentaram médias fenotípicas elevadas, reduzida variância ambiental e semelhança entre genótipos. De maneira que a seleção fenotípica seria inviável em Tupaciguara, pois as sementes dos genótipos de soja não apresentaram diferenças significativas para a característica germinação, e se não existe variabilidade não existe seleção.

A maior importância da herdabilidade em estudos genéticos de caráter métrico, é o papel preditivo por expressar a confiança do valor fenotípico como guia genético ou o grau de correspondência entre os valores fenotípico e genético (FALCONER, 1987). O coeficiente de determinação genotípico é um parâmetro relacionado à herdabilidade, contudo, possibilita inferências a cerca de genótipos (efeito fixo) e não da população (efeito aleatório) no caso da herdabilidade. O coeficiente de determinação genotípico foi de $43,12 \%$, para a germinação de sementes, e de $57,16 \%$, para a emergência de plântulas em leito de areia (Tabela 6). Isso indica que de toda a variação observada aproximadamente metade dela é de origem genética e a outra metade possivelmente está relacionada a desvios experimentais. 
Tabela 5. Quadrados médios e parâmetros genéticos estimados a partir dos dados do teste de germinação e de emergência de plântulas das sementes de cultivares e linhagens de soja dos ensaios conduzidos em diferentes ambientes no Estado de Minas Gerais. Ano agrícola 2000/2001².

\begin{tabular}{clllllllll}
\hline \multirow{2}{*}{ Teste } & Ambientes & QMB & QMG & QMR & \multicolumn{2}{c}{ Média } & CV & $\hat{\phi}_{\mathrm{g}}$ & $\mathrm{H}^{2}$ \\
& & & & & & & & & \\
\multirow{5}{*}{ Germinação } & Capinópolis1 & 0,016 & $0,028^{* *}$ & 0,011 & 87,30 & 1,224 & 8,409 & 0,0059 & 0,6249 \\
& Capinópolis2 & 0,002 & $0,018^{*}$ & 0,009 & 87,92 & 1,229 & 7,812 & 0,0030 & 0,4920 \\
& lupaciguara & 0,001 & $0,005^{\text {ns }}$ & 0,005 & 98,51 & 1,471 & 5,058 & 0,0000 & 0,0000 \\
& Florestal & 0,000 & $0,032^{* *}$ & 0,011 & 89,36 & 1,259 & 8,211 & 0,0071 & 0,6661 \\
& Unaí & 0,008 & $0,016^{*}$ & 0,007 & 83,28 & 1,158 & 7,108 & 0,0030 & 0,5720 \\
\hline \multirow{5}{*}{ Emergência } & Capinópolis1 & 0,034 & $0,036^{* *}$ & 0,010 & 84,65 & 1,186 & 8,5083 & 0,0086 & 0,7166 \\
& Capinópolis2 & 0,016 & $0,018^{*}$ & 0,008 & 88,37 & 1,236 & 7,0727 & 0,0033 & 0,5630 \\
& Tupaciguara & 0,005 & $0,020^{* *}$ & 0,005 & 96,53 & 1,409 & 5,0448 & 0,0048 & 0,7420 \\
& Florestal & 0,010 & $0,045^{* *}$ & 0,011 & 88,02 & 1,241 & 8,4527 & 0,0113 & 0,7556 \\
& Unaí & 0,021 & $0,015^{* *}$ & 0,005 & 85,45 & 1,188 & 5,9884 & 0,0033 & 0,6642 \\
\hline
\end{tabular}

QMB-Quadrado médio de blocos; QMG- Quadrado médio dos genótipos; QMR- Quadrado médio do resíduo; CV-Coeficiente de variação experimental; $\hat{\phi}_{\mathrm{g}}$ - Componente quadrático genotípico; $\mathrm{H}^{2}$ - coeficiente de determinação genotípico; * e **- significativo pelo teste F a 5\% e 1\% respectivamente; ns- não significativo pelo teste F; ${ }^{1}$ - Análises feitas com os dados transformados em arcoseno $\sqrt{x / 100}$.

Tabela 6. Parâmetros genéticos estimados a partir da análise conjunta dos ambientes, das variáveis germinação e emergência de plântulas em leito de areia, das sementes de linhagens e cultivares de soja em cinco ambientes do Estado de Minas Gerais. Ano agrícola 2000/2001².

\begin{tabular}{|c|c|c|}
\hline Parâmetro genético & Teste de germinação & ELA* \\
\hline Média & $89,275^{2}$ & $88,604^{2}$ \\
\hline Coeficiente de variação experimental (\%) & 7,2963 & 7,0488 \\
\hline Componente quadrático genotípico & 0,0009 & 0,0019 \\
\hline Componente de variância GxA ${ }^{3}$ & 0,0027 & 0,0042 \\
\hline Variância residual & 0,0086 & 0,0078 \\
\hline Coeficiente de determinação genotípico (\%) & 43,1187 & 57,1604 \\
\hline Coef. Variação genético (\%) & 2,3298 & 3,4529 \\
\hline Razão CVg/CV & 0,3193 & 0,4899 \\
\hline
\end{tabular}

* - Teste de emergência em leito de areia; ${ }^{1}$ - Análises feitas com os dados do teste de germinação transformados em arcoseno $\sqrt{x / 100} ;{ }^{2}$ - Média original; ${ }^{3}$ - Componente de variância da interação genótipos x ambientes.

O coeficiente de variação genético foi de $2,32 \%$, para os dados transformados de germinação (Tabela 6). Esse coeficiente expressa, em percentagem, a fração genética na média do experimento. Os dados transformados do teste de germinação mostram razão entre o coeficiente de variação genotípico e o de variância ambiental de 31,93\% (Tabela 6). A razão entre o coeficiente de variância genético $(\mathrm{CVg})$ e o ambiental (CV) mostra a parte da variância total que é explicada pelo genótipo. Esses resultados apontam para uma seleção com efeito semelhante, ou melhor, ao obtido na seleção para produtividade de plantas que tem herdabilidade 20 e $40 \%$ (DI MAURO et al., 2000) de maneira geral, indicando que selecionar 
para germinação de sementes pode levar a ganhos genéticos para essa característica.

\section{Emergência de plântulas}

A análise de variância conjunta dos diferentes locais foi realizada sem o ajuste dos graus de liberdade do resíduo e da interação (Tabela 2) uma vez que o quociente entre o maior quadrado médio residual e o menor foi de 2,178 .

O coeficiente de variação dos dados da emergência de plântulas em leito de areia foi 7,05\% (Tabela 2) próximo ao obtido para sementes de soja (9,55\%), por Gondim et al. (2002), evidenciando precisão experimental próxima ao que tem sido verificado em experimentos de soja.

A interação genótipos $\mathrm{x}$ ambientes, para os dados transformados de emergência de plântulas em leito de areia, também foi significativa, evidenciando comportamento variado dos genótipos nos diferentes ambientes.

A porcentagem e os valores transformados para arco seno $\sqrt{x / 100}$ da emergência de plântulas em leito de areia das sementes de soja foram maiores para as sementes produzidas em Tupaciguara (Tabela 4), evidenciando que esse ambiente proporcionou, de maneira geral, melhor condições para a melhoria da qualidade das sementes.

O genótipo UFV98-467150 apresentou maior índice de plântulas emergidas em leito de areia (97\%) em Capinópolis 1 (em Latossolo vermelho eutroférrico). Enquanto que em Capinópolis 2 (Latossolo vermelho distroférrico) Doko-RC, UFV97-6129726 e UFV99-61270 (93; 94; 94,33\% de emergência, respectivamente) foram os materiais com maior índice de plântulas emergidas em leito de areia. Os genótipos Doko-RC e UFV97-6129729 (99 e 99,67\%, respectivamente) apresentaram maiores índices de emergência de plântulas em Tupaciguara (Tabela 4).

A linhagem UFV99-806241 apresentou o menor índice de porcentagem de plântulas emergidas
(58,67\%) em Florestal, e Conquista e UFV976119091 (ambas com 91,67\%) o maior índice nesse mesmo local. A cultivar FT 104 apresentou maior índice de percentagem de plântulas emergidas (92,33\%) enquanto a linhagem UFV976119091 apresentou o menor $(73,67 \%)$ em Unaí (Tabela 4). Esses resultados estão relacionados à variabilidade existente para essa característica, já que nos diferentes ambientes, materiais distintos se sobressaíram.

Os valores dos parâmetros genéticos e dos quadrados médios de blocos, de genótipos, e do resíduo, estimados para os dados transformados de plântulas emergidas em leito de areia, geraram maior estimativa do componente quadrático genotípico para as sementes em Florestal $(0,0113)$ e maior valor do coeficiente de determinação genotípico (75,56\%) (Tabela 5). As sementes de Capinópolis 1 e Tupaciguara (71,61 e 74,20\%, respectivamente), também, apresentaram coeficiente de determinação genotípico semelhantes aos de Florestal. A variável emergência de plântulas em leito de areia mostrou, em geral, mais de $55 \%$ da variância fenotípica devida à variabilidade entre genótipos.

O coeficiente de variação genético foi de $3,45 \%$, para os dados transformados da emergência de plântulas em leito de areia (Tabela 6) com razão entre o coeficiente de variação genotípico e o de variância ambiental de 48,99\%. Esses resultados refletem a relação entre o erro experimental e o efeito genético existente entre os materiais avaliados, mostrando que grande parte da variância existente é de origem genética, isso favorece o processo de seleção para essa característica, pelo aumento da chance de ganho genético.

O coeficiente de determinação genotípico indica que a seleção pode apresentar maior eficiência em ambientes individuais que naqueles conjuntamente. Isso ocorre, quando os valores do coeficiente de determinação genotípico são maiores em cada ambiente, que quando obtido pela análise de variância conjunta. Os ganhos com a seleção podem ser maximizados quando for realizada em um dado 
ambiente, pois a interação genótipos $\mathrm{x}$ ambientes é utilizada no processo seletivo. Entretanto, a seleção em ambientes individuais terá genótipos adaptados a ambientes específicos, sendo dessa forma mais eficiente.

\section{Conclusões}

A germinação das sementes das cultivares FT 104, Doko-RC e Conquista e das linhagens UFV9761190916 e UFV98-CR67 foi maior que 85\% em todos os ambientes.

Os coeficientes de determinação genotípico, obtidos a partir dos dados de germinação de sementes e de emergência de plântulas em leito de areia, variaram entre ambientes.

A seleção de genótipos de soja para a qualidade fisiológica das sementes, por local, pode propiciar maiores ganhos do que a seleção que considera todos os ambientes conjuntamente.

\section{Referências}

BONATO, E. R.; VELLO, N. A. Aspectos genéticos do tempo para o florescimento em variantes naturais de soja. Pesquisa Agropecuária Brasileira, Brasília, v. 34, n. 6, p. 989-993, 1999.

BRASIL. Ministério da Agricultura. Secretaria Nacional de Defesa Agropecuária. Regras para a análise de sementes. Brasília. 1992, 365 p.

CARRARO, I. M.; PESKE, S. T. Uso de sementes de soja no Estado do Paraná. Revista Brasileira de Sementes, Pelotas, v. 27, n. 2, p. 75-80, 2005.

CILAS, C.; BOUHARMONT, P.; BOCCARA, M.; ESKES, A. B.; BARADAT, P. Prediction of genetic value for coffee production in Coffea arabica from a halfdiallel with lines and hybrids. Euphytica, Dordrecht, v. 104, n. 1, p. 49-59, 1998.

COIMBRA, J. L. M.; GUIDOLIN, A. F.; CARVALHO, F. I. F. Parâmetros genéticos do rendimento de grãos e seus componentes com implicações na seleção indireta em genótipos de feijão preto. Ciência Rural, Santa Maria, v. 29, n. 1 , p. 1-6, 1999.

CRUZ, C. D. Programa GENES: estatística experimental e matrizes. Viçosa: UFV, 2006. 285 p.
CRUZ, C. D.; REGAZZI, A. J. Modelos biométricos aplicados ao melhoramento genético. Viçosa: UFV, 1997. $390 \mathrm{p}$.

DI MAURO, A. O.; OLIVEIRA, R. C.; MARCONDES, A. F.; SEDIYAMA, T. Ganho genético por seleção em linhagens de soja. Revista Ceres, Viçosa, v. 270, n. 47, p. 135-144, 2000.

FALCONER, D. S. Introdução à genética quantitativa. Viçosa: UFV, 1987. 279 p.

GOMES, F. P. Curso de estatística experimental. Piracicaba: Nobel, 1985. 466 p.

GONDIM, T. C. O.; SEDIYAMA, C. S.; ROCHA, V. S. E.; MOREIRA, M. A. Qualidade fisiológica de sementes de linhagens de soja com presença ou ausência de lipoxigenases, em diferentes épocas de colheita. Revista Brasileira de Sementes, Pelotas, v. 24, n. 1, p. 141-147, 2002.

GRAVINA, G. A.; MARTINS FILHO, S.; SEDIYAMA, C. S.; CRUZ, C. D. Parâmetros genéticos da resistência da soja a Cercospora sojina. Pesquisa Agropecuária Brasileira, Brasília, v. 39, n. 7, p. 653-659, 2004.

GRAVOIS, K. A.; BERNHARDT, J. L. Heritability x environment interactions for discoloured rice kernels. Crop Science, Madison, v. 40, n. 2, p. 314-318, 2000.

HEGSTAD, J. M.; BOLLERO, G.; NICKELL, C. D. Potential using plant row yield trials to predict soybean yield. Crop Science, Madison, v. 39, n. 6, p. 1671-1675, 1999.

LACERDA, A. L. S.; LAZARINI, E.; SÁ, M. E.; VALÉRIO FILHO, W. V. Armazenamento de sementes de soja dessecadas e avaliação da qualidade fisiológica, bioquímica e sanitaria. Revista Brasileira de Sementes, Pelotas, v. 25, n. 2, p. 97-105, 2003.

LIMA, W. F.; PÍPOLO, A. E.; MOREIRA, J. U. V.; CARVALHO, C. G. P. de; PRETE, C. E. C.; ARIAS, C. A. A.; OLIVEIRA, M. F. de; SOUZA, G. E. de; TOLEDO, J. F. F. de. Interação genótipo-ambiente de soja convencional e transgênica resistente a glifosato, no Estado do Paraná. Pesquisa Agropecuária Brasileira, Brasília, v. 43, n. 6, p. 729-736, 2008.

PÁDUA, G. P. de; ZITO, R. K.; ARANTES, N. E.; FRANÇA NETO, J. de B. Influência do tamanho da semente na qualidade fisiológica e na produtividade da cultura da soja. Revista Brasileira de Sementes, Pelotas, v. 32, n. 3, p. 09-16, 2010.

PEREIRA, E. B. C.; PEREIRA, A. V.; FRAGA, A. C. Qualidade de sementes de cultivares precoces de soja produzidas em três épocas. Pesquisa Agropecuária Brasileira, Brasília, v. 35, n. 8, p.1653-1662, 2000. 
SANTOS, M. R.; REIS, M. S.; SEDIYAMA, T.; CECON, P. R.; DIAS, D. C. F. S. Germinação e qualidade sanitária de sementes de soja produzidas em diferentes regiões do estado de Minas Gerais. Revista Ceres, Viçosa, v. 48, n. 276, p.127-139, 2001.

SOOD, O. P.; SOOD, V. K.; ANAND, D.; KALIA, N. R. Phenotypic stability for yield and maturity in soybean (Glycine max) in mid-hills of Himachal Pradesh. Indian Journal of Agricultural Sciences, New Delhi, v. 69, n. 7, p. 536-537, 1999.
STRICKBERGER, M. W. Genetics. New York: The McMillan, 1985. 842 p.

YANG, C. I.; YANG, S. J.; JEOUNG, Y. P.; CHOI, H. C.; SHIN, Y. B. Genotyperenvironment interaction of rice yield in multi-location trials. Korean Journal of Crop Science, Korea, v. 46, n. 1, p. 453-458, 2001. 